\title{
Relações entre professores, alunos e cadernos: sistematizações de uma pesquisa-intervenção
}

\author{
Relationships between teachers, students and notebooks: \\ intervention-research systematization
}

\section{Relaciones entre profesores, estudiantes y cuadernos: sistematizaciones de una intervención-investigación}

\author{
Simone Regina Manosso Cartaxo 1 \\ https://orcid.org/0000-0002-8670-6324 \\ Josiane Cristina Dittmar Pimentel 2 \\ https://orcid.org/0000-0002-7008-264|
}

\begin{abstract}
Resumo: A relação entre professor, aluno e caderno é discutida neste artigo a partir do questionamento sobre como ocorrem os processos de intervenção do professor no caderno do aluno. É uma pesquisa-intervenção que considera o contexto escolar pesquisado, a participação dos sujeitos (professores, alunos e pais) e a ação do pedagogo pesquisador no processo de ensino. $O$ objetivo é sistematizar descobertas e elaborações teóricometodológicas a partir de problemas da prática pedagógica. Como pressuposto para os processos de intervenção na escola, tomou-se a educação como uma produção histórica e social. Estudar esses processos requer considerar as trajetórias do coletivo e o contexto, não se admitindo a proposição de modelos universais e generalizáveis. A partir dos problemas postos pela prática, buscar situá-la historicamente, contextualizá-la, encontrar explicações teóricas de modo a chegar em sua reelaboração por meio da sistematização coletiva. As sistematizações coletivas apontaram aspectos a serem observados na reformulação da prática de intervenção no caderno do aluno: repensar o protagonismo do aluno no uso dos cadernos; qualificar o caderno como instrumento de acompanhamento individual dos processos de aprendizagem; explicitar aos pais como ocorrem os processos de intervenção no caderno do aluno.
\end{abstract}

Palavras-chave: Prática pedagógica. Experiência coletiva. Pesquisa.

Abstract: The relationship between teacher, student and notebook is discussed in this paper by questioning the kind of intervention processes that are developed by teachers in students' notebooks. This is intervention research was developed considering the school context investigated, the participants (teachers, students, parents) and the action of the researcher educator in the teaching process. The objective is to systematize findings and

\footnotetext{
' Doutora em Educação. Professora do Departamento de Pedagogia e do Programa de Pós-Graduação em Educação - UEPG. E-mail: simonemcartaxo@hotmail.com.

${ }^{2}$ Graduada em Pedagogia com especialização em Psicopedagogia e Educação Inclusiva. Pedagoga da Rede Municipal de Ensino de Curitiba. E-mail: jodittmarp@gmail.com.
}

Olhar de professor, Ponta Grossa, v. 24, p. I-15, e-15398.004, 2021.

Disponível em <https://revistas2.uepg.br/index.php/olhardeprofessor> 
theoretical-methodological elaborations from the problems faced in the teaching practice. Education as historical and social production was taken as a premise for the intervention processes in schools. Studying these processes requires the consideration of collective trajectories and the context under analysis, without the assumption of universal and general models. From the problems encountered in the teaching practice, this study seeks to situate it historically and contextualize it to find theoretical explanations to re-elaborate it through collective systematization. Collective systematizations pointed out aspects to be observed when reformulating the intervention practice in the students' notebooks such as rethinking the students' protagonist action when using their notebooks, qualifying the notebook as a tool to monitor the individuals' learning processes, and explaining to parents what kind of intervention occurs in the students' notebooks.

Keywords: Teaching practice. Collective experience. Research.

Resumen: La relación entre el maestro, el alumno y el cuaderno se discute en este artículo cuestionando cómo ocurren los procesos de intervención del maestro en el cuaderno del alumno. Es una intervención-investigación que considera el contexto escolar investigado, la participación de los sujetos (docentes, alumnos y padres) y la acción del pedagogo investigador en el proceso de enseñanza. El objetivo es sistematizar descubrimientos y elaboraciones teórico-metodológicas basadas en problemas de la práctica pedagógica. Como condición previa para los procesos de intervención en la escuela, la educación se concibe como una producción histórica y social. Estudiar estos procesos requiere considerar las trayectorias del colectivo y el contexto, sin admitir la proposición de modelos universales y generalizables. Con base en los problemas planteados por la práctica, buscamos situarla históricamente, contextualizarla, encontrar explicaciones teóricas para llegar a su reelaboración a través de la sistematización colectiva. Las sistematizaciones colectivas señalaron aspectos a observar en la reformulación de la práctica de intervención en el cuaderno del alumno: repensar el papel del alumno en el uso del cuaderno; calificar al cuaderno como instrumento para el acompañamiento individual de los procesos de aprendizaje; explicar a los padres cómo se producen los procesos de intervención en el cuaderno del alumno.

Palabras-clave: Práctica pedagógica. Experiencia colectiva. Investigación.

\section{Introdução}

Este artigo versa sobre uma pesquisa-intervenção, realizada por profissionais de uma coordenação pedagógica ${ }^{3}$, nos anos iniciais de uma escola de educação básica, a partir da necessidade de pensar sobre as ações do professor no caderno do aluno. A problemática definida para a pesquisa parte dos seguintes questionamentos: Como o professor faz a intervenção no caderno do aluno? Por que o faz? Quando o faz? O que a determina? E o aluno, o que pensa sobre o seu caderno e sobre essa ação do professor?

Os estudos de Hébrard (1995) e Gvirtz (1999) destacaram o caderno escolar como um proeminente objeto que oferece pistas importantes sobre o cotidiano da escola. Mignot (2008) explica que os cadernos escolares têm passado por uma valorização, como objeto ou fonte de pesquisa, envolvendo historiadores da educação, especialistas em currículo e formação de professores, a fim de examinar o vivido na sala de aula. Nas palavras de Chartier (2007, p.13), os cadernos podem fornecer “testemunhos insubstituíveis a respeito dos exercícios escolares, das práticas pedagógicas e do desempenho dos alunos no contexto da sala de aula”.

\footnotetext{
${ }^{3}$ Este relato de experiência foi elaborado por coordenadoras pedagógicas de uma escola pública e está articulado à proposta que organiza o trabalho pedagógico da instituição.
} 
Em concordância com os autores acerca da afirmação de que os cadernos escolares expressam práticas pedagógicas realizadas na escola, compreendemos que essas práticas revelam concepções a respeito das relações estabelecidas entre professores e alunos. As práticas são intencionais e expressam uma concepção de mundo, sociedade e educação que se articula às relações sociais e, por sua vez, podem ser conservadoras ou transformadoras.

Pesquisadores têm enfatizado que o caderno é também uma forma que a família tem de acompanhar o desenvolvimento do aluno em relação à aprendizagem e à organização escolar (HÉBRARD, 200I; PERES; PORTO, 2009). Esse é um aspecto que pode ser determinante na organização de práticas intencionais realizadas na escola, de modo a atender expectativas requeridas pela comunidade escolar.

E foi exatamente a relação da família com o caderno que desencadeou questionamentos sobre a intervenção do professor sobre este artefato escolar. O ponto de partida para a pesquisa-intervenção (MOREIRA, 2008) foi o questionamento de familiares sobre a ausência de marcas - como correções, incentivos, pareceres escritos pelos professores - nos cadernos dos alunos.

A estratégia de pesquisa-intervenção foi escolhida, pois prioriza a atuação dos sujeitos no seu contexto e é direcionada pela ideia de processo, possibilitando a intervenção na prática pedagógica. Neste sentido, a pesquisa e o texto que segue têm como objetivo sistematizar descobertas e elaborações teórico-metodológicas a partir de problemas da prática pedagógica.

Esta forma de pensar articula-se ao conceito de prática pedagógica como dimensão da prática social voltada para os processos formativos, pedagógicos, políticos e culturais. Nessas práticas, são reconhecidos determinantes internos e externos. Os determinantes externos manifestam-se na forma de controle de práticas que atendem mais a resultados do que a processos. Os determinantes internos estão presentes nas formas de organizar o trabalho pedagógico na escola como as rotinas, relações hierárquicas entre os profissionais, as famílias e os alunos (SOUZA, 20I6).

O questionamento que originou esta pesquisa-intervenção surge de um determinante interno (família questionando a ação da escola) que, por sua vez, recebe influências de determinantes externos (testes seletivos, concursos, provas em larga escala) que impulsionam ações mais competitivas e individualistas.

A opção para a solução do problema posto pela prática foi estabelecer relações coletivas entre os sujeitos do processo de ensino. Bernardo (2009) explica que as formas de resistência individuais "reproduzem ao mesmo tempo a fragmentação em que se encontram e reforçam as bases do capitalismo" (BERNARDO, 2009, p. 336-337). Já nas resistências coletivas, a possibilidade de um organismo único abraçando a globalidade dos participantes possibilita a superação da fragmentação, uma vez que há produção coletiva de conhecimento. 
Relações entre professores, alunos e cadernos: sistematizações de uma pesquisa-intervenção

Dado o questionamento das famílias, foi necessário buscar formas de respondê-lo considerando os sujeitos envolvidos no processo de ensino. $\mathrm{O}$ acompanhamento do trabalho nas salas de aula possibilitou observar os cadernos dos alunos e os processos interativos entre professores e alunos. Destacaram-se nessas observações as formas diferenciadas de organização da aula, dos registros realizados nos cadernos, dos diálogos estabelecidos entre os sujeitos envolvidos nos processos interativos, compreendidos de forma contextualizada.

Ora, estabelecer previamente critérios de verificação dos materiais dos alunos, como forma de controle pela equipe gestora, desconsideraria a autoria do processo de ensino dos professores. Há professores que interagem o tempo todos com os alunos, apontando possibilidades, acompanhando estratégias de registro e estimulando a produção com incentivos. São ações verbalizadas que se tornam invisíveis aos olhos de quem está de fora. Como destaca Viñao (2008, p. 25), ao explicar que nem tudo está presente nos cadernos, "eles silenciam, não dizem nada sobre as intervenções orais ou gestuais do professor e dos alunos [...] sobre o ambiente ou clima da sala de aula".

Assim, a proposta foi realizar uma intervenção considerando as possibilidades de uma sistematização coletiva, pressupondo que o "conhecimento consiste em produtos de práticas humanas no seio das relações sociais de uma formação social concreta e responde a necessidades humanas práticas" (SANTOS, 1984, p. 5). Nesta perspectiva, é assumido um modelo epistemológico em que a teoria é concebida como expressão da prática (MARTINS, 1996), com o compromisso de orientar a prática pedagógica a partir do que os sujeitos possuem, do conhecimento que eles têm, da forma como foi produzido, de suas práticas, experiências e necessidades.

Como pressuposto para os processos de intervenção na escola, tomou-se a educação como uma produção histórica e social. Estudar esses processos requer considerar as trajetórias do coletivo e o contexto, não se admitindo a proposição de modelos universais e generalizáveis. A partir dos problemas postos pela prática, buscar situá-la historicamente, contextualizá-la, encontrar explicações teóricas de modo a chegar em sua reelaboração por meio da sistematização coletiva.

Diante do exposto, a pesquisa-intervenção assume um papel formativo com vistas à transformação da prática pedagógica. Para apresentar os resultados da intervenção, o texto que segue a partir desta introdução apresenta a metodologia com os procedimentos de pesquisa, acompanhado das etapas desenvolvidas junto aos sujeitos participantes e as sistematizações coletivas decorrentes das análises realizadas.

\section{Metodologia}

A pesquisa-intervenção foi a opção para pensar coletivamente sobre a relação dos professores com os cadernos dos alunos. Foram considerados dois princípios que norteiam este tipo de pesquisa, 
como destaca Moreira (2008): as realidades sociais e cotidianas e o compromisso ético e político da produção de práticas inovadoras. Esses princípios englobam orientações fundamentais para o desenvolvimento da pesquisa: acontecer dentro do contexto pesquisado; atender uma demanda de forma a contribuir para a solução de problemas; ter o pesquisador como mediador que articula, organiza e sistematiza as falas dos sujeitos envolvidos; conceber que as experiências cotidianas e práticas do coletivo, sistematizadas, permitem descobertas e elaborações teórico-metodológicas.

Como procedimentos de pesquisa, foram aplicados questionários com questões abertas (FLICK, 2009) aos professores, alunos e pais de alunos, bem como realizados grupos de discussão (FLICK, 2009) com professores e com alunos. Também foram observados os cadernos e as salas de aula pelas coordenadoras pedagógicas de uma escola.

O questionário aplicado aos professores buscou recolher informações sobre a função do caderno, a intervenção do professor no caderno do aluno, os desafios para o uso do caderno, a percepção do professor sobre a relação dos alunos com os cadernos e as possibilidades de realizar registros escolares em outros suportes. Ao todo, foram respondidos 12 questionários de um total de 16 distribuídos. O questionário aplicado aos pais contemplou questões similares à dos professores. No total, foram recolhidos 8 dos 14 questionários distribuídos aos pais.

Concomitantemente, foram aplicados questionários com 2 grupos de alunos do quarto e quintos anos. As questões abordaram a função e formas de uso do caderno. Foram selecionados I4 alunos, considerando diferentes níveis de aprendizagem e formas de organização e uso do caderno (cadernos considerados pelas professoras como exemplares e cadernos com registros incompletos). Ao todo, foram coletados 14 questionários.

O grupo de discussão foi realizado com 6 estudantes do $5^{\circ}$ ano do ensino fundamental e teve como objetivo discutir as questões propostas no questionário, a fim de aprofundar as respostas. Foram escolhidos os estudantes do quinto ano por terem mais tempo de frequência no ensino fundamental.

Os grupos de discussão com os professores foi realizado em três momentos: dois pequenos grupos durante a hora-atividade e um grupo com todos os profissionais da escola durante uma reunião pedagógica. As discussões partiram da análise das respostas dos questionários para formular propostas de reformulação da prática dos professores em relação ao caderno dos alunos.

A sistematização dos dados foi coletiva e fundamentou-se em Martins (1996). Esta sistematização coletiva é constituída por momentos, fundamentais e inter-relacionados: I) Caracterização e problematização da prática pedagógica dos professores de forma a captar como ela transcorre; 2) Explicação da prática mediatizada por um referencial teórico, entendendo que essa prática é uma síntese de múltiplas determinações; 3) Compreensão da prática no nível da totalidade, 
Relações entre professores, alunos e cadernos: sistematizações de uma pesquisa-intervenção

buscando as raízes mais profundas dos seus determinantes no nível da totalidade com discussões acerca dos determinantes históricos, sociais, políticos; 4) Elaboração de propostas para intervenção na prática.

\section{O caderno escolar: o que dizem os alunos, os professores e os pais}

Os dados obtidos com os questionários foram mapeados e assim categorizados: a função do caderno escolar; a intervenção do professor no caderno do aluno; e a autoria do aluno no uso do caderno escolar.

a) A função do caderno escolar

Para Viñao (2008), o caderno pode ter funções diferentes, dependendo do contexto. Por ser um produto da cultura escolar, permite enxergar práticas pedagógicas e, nesta perspectiva, o uso do caderno expressa a função a ele dada.

A compreensão sobre a função do caderno foi buscada entre os professores, alunos e pais. A primeira leitura possibilitou recolher as ideias expressas nas respostas dos respondentes, que foram organizadas no Quadro I.

Quadro I: Função do caderno

\begin{tabular}{|c|c|c|}
\hline Professor & Aluno & \multirow{11}{*}{$\begin{array}{c}\text { Pais } \\
\text { Fixar a matéria } \\
\text { Fixar conhecimento } \\
\text { Treinar } \\
\text { Expressão (parcial) } \\
\text { Ajudar no asseio do material } \\
\text { Prática de escrita manual } \\
\text { Fazer lição } \\
\text { Acompanhamento da família } \\
\text { Verificar a letra } \\
\text { Identificar a dificuldade } \\
\text { Controlar e acompanhar } \\
\text { desempenho }\end{array}$} \\
\hline $\begin{array}{c}\text { Registrar conteúdo; } \\
\text { Registrar ideias/pensamentos }\end{array}$ & \multirow{10}{*}{$\begin{array}{c}\text { Escrever a matéria } \\
\text { Guardar a matéria } \\
\text { Estudar } \\
\text { Aprender } \\
\text { Lembrar } \\
\text { Anotar } \\
\text { Mostrar à família } \\
\text { Estudar para a prova } \\
\text { Explicar o que fez de } \\
\text { lição } \\
\text { Ajudar na aprendizagem }\end{array}$} & \\
\hline Registrar atividades/exercícios & & \\
\hline Avaliar/reavaliar & & \\
\hline Organizar & & \\
\hline Aprendizagem & & \\
\hline Como o aluno aprende & & \\
\hline Documento histórico & & \\
\hline Diário & & \\
\hline Portfólio & & \\
\hline Acompanhamento familiar & & \\
\hline
\end{tabular}

Fonte: As autoras, 2017.

Esta primeira síntese indicou três pontos centrais que os professores pensam sobre a função do caderno: acompanhamento da aprendizagem como processo (por parte da escola e da família); da aprendizagem como percurso individual (portfólio-diário); registro e organização formal do conteúdo.

A síntese que emergiu das respostas dos alunos destacou a função do caderno relacionando-o ao estudo e à aprendizagem, como documento comprobatório da aprendizagem e prestação de contas; uso determinado pelo professor com restrições; fonte de estudo para prova.

Para os alunos perguntou-se, também, "Quando o caderno deve ser usado e por quê?". As respostas indicaram: durante a aula; quando o professor escreve no quadro; quando o professor manda; para estudar para prova; para fazer lição; para lembrar; ajudar nas dúvidas. Apontaram ainda 
restrições como não desenhar nele e não rasgá-lo. Sobre isso, concordamos com Chartier (2001; 2005 apud VIÑAO, 2008) ao explicar que o caderno converte-se implacavelmente em instrumento inculcador do saber escolar legítimo (e ilegítimo), por meio do conhecimento daquilo que se pode ou não escrever nele e como escrever.

Nas respostas dos pais sobre a função do caderno, a síntese realizada destaca a concepção de processo de aprendizagem e desenvolvimento; forma de controle da família e da escola; forma de organização (prioridade para a letra).

As questões da organização do caderno também são enfatizadas pelos professores. Sobre isso, Viñao (2008) destaca que, ao analisar a cultura do caderno escolar e se perguntar o que é considerado como um bom trabalho escolar, encontrar-se-á destaque para a forma em detrimento do conteúdo. Explica que, além dos elementos de apresentação do caderno utilizados no cotidiano (cabeçalho, títulos, ornamentações), dá-se ênfase "à 'limpeza' e à ausência de manchas, folhas arrancadas ou anotações e desenhos intempestivos ou 'selvagens', não controlados" (VIÑAO, 2008, p.23). Para o autor, a razão disso é o efeito estético e ético, regularizador e disciplinador, que visa criar hábitos não transgressores e moralizadores.

A observação inicial dos cadernos realizado pelas coordenadoras pedagógicas indicou, entre outros aspectos, que neles preponderam as cópias e os exercícios, caracterizando formas padronizadas de organização. Ora, se todos os cadernos contêm os mesmos elementos, registrados da mesma forma, mostram o processo de aprendizagem conforme expressaram os professores? É possível ver o percurso de aprendizagem do aluno?

b) A intervenção do professor no caderno do aluno

A análise da intervenção do professor no caderno do aluno decorreu das respostas sobre quando, como e os motivos pelos quais os professores devem intervir. O Quadro 2 apresenta uma síntese das respostas obtidas:

Quadro 2: A intervenção do professor no caderno do aluno

\begin{tabular}{|c|c|c|}
\hline Professor & Aluno & Pais \\
\hline $\begin{array}{c}\text { Interagir } \\
\text { Orientar a organização do aluno } \\
\text { Orientar o aluno para que realize a } \\
\text { tarefa com confiança } \\
\text { Cuidar de como o aluno faz a } \\
\text { correção } \\
\text { Ocorrer durante e depois das tarefas } \\
\text { Auxiliar no avanço da aprendizagem } \\
\text { Diagnosticar }\end{array}$ & $\begin{array}{c}\text { Apontar os } \\
\text { erros } \\
\text { Corrigir os erros } \\
\text { Elogiar } \\
\text { Completar a } \\
\text { tarefa do aluno }\end{array}$ & $\begin{array}{l}\text { Corrigir tarefa de casa } \\
\text { Mostrar a importância dada à } \\
\text { tarefa (frustração quando não é } \\
\text { realizada a correção) } \\
\text { Mostrar pontos a desenvolver } \\
\text { Cuidar para não constranger } \\
\text { Mostrar evolução } \\
\text { Possibilitar ao aluno "sentir" o } \\
\text { acompanhamento do professor } \\
\text { Estabelecer confiança }\end{array}$ \\
\hline
\end{tabular}

Fonte: As autoras, 2017

Olhar de professor, Ponta Grossa, v. 24, p. I-15, e-15398.004, 202 I.

Disponível em <https://revistas2.uepg.br/index.php/olhardeprofessor> 
Destacamos, nas respostas sobre a intervenção no caderno do aluno, alguns pontos: a) ela é necessária, pois leva à aprendizagem e funciona como suporte para identificar pontos a serem desenvolvidos; b) é preciso que ocorra em um clima de confiança, cuidando para não reforçar o erro e constranger o aluno; c) deve ser realizada em diferentes momentos para atender às expectativas do professor (conhecer a aprendizagem do aluno), do aluno (para certificar-se de que está no caminho certo) e dos pais (para estarem certos de que o professor acompanha o aluno).

Sobre as relações estabelecidas entre professor e aluno, identificamos que elas são verticalizadas: os alunos depositam no professor a autoridade de saber o que está certo ou errado e o aluno tem expectativa do acompanhamento do professor para apontar erros e receber elogios.

As práticas de intervenção do professor no caderno do aluno e as relações estabelecidas precisam ser compreendidas no contexto em que são produzidas. Neste sentido, concordamos com Lopes (2008) quando afirma que a atividade docente decorre de experiências individuais, estabelecidas nas relações interpessoais entre professores e alunos, estando condicionada a questões afetivas e sociais. Os professores trazem repertórios pessoais, que se originaram na forma como cada um interiorizou a diversidade cultural experimentada.

\section{c) A autoria do aluno no uso do caderno escolar}

A discussão sobre a autoria do aluno no uso do caderno emergiu das respostas dos pais e alunos nos questionários e do grupo de discussão com os alunos.

Existem diferentes formas de planejar o uso do caderno, uma vez que esse uso decorre de concepções de ensino. Sobre esta questão específica da relação do aluno com o caderno, destacam-se respostas dos pais:

Uma vez tive em mãos cadernos de alunos do $9^{\circ}$ ano de uma escola Waldorf. Eram belíssimos, obras de arte. Desde o $I^{\circ}$ ano, as crianças são incentivadas a desenhar o que aprendem. $O$ professor introduz o conhecimento e anota no quadro. As crianças copiam no caderno, com letra de forma. A outra parte das anotações é desenvolvida pelas crianças, com letra cursiva, onde precisam "relatar" o que entenderam a partir do que foi ensinado. Bom treino para redação e síntese (Mãe I- questionário).

Ao analisar o caderno do filho, a mãe responde ao questionário, destacando:

Os meus gostam dos cadernos, numa visão geral. Ambos gostam de desenhar e principalmente o mais velho, enche as páginas de rabiscos. Fico dividida entre exigir que ele cuide bem do material e o fato de adorar encontrar esses "tesourinhos" desenhados no meio das matérias. (Mãe l- questionário).

Outros pais fizeram críticas: 
Acredito que ainda tem muita cópia de matéria (Pai-2);

O caderno tem poucos desafios para a capacidade dele (Pai 3).

Esses exemplos indicam a percepção dos pais sobre o protagonismo - ou a falta dele - dos alunos em relação ao uso do caderno.

No grupo de discussão com os alunos, emergiram conversas a respeito da capa do caderno, da forma de utilizar os espaços (número de linhas para cada exercício, possibilidade de desenhar e função do caderno). Nas palavras dos alunos:

Porque, se ele fosse diferente, eu poderia fazer várias coisas, como fazer desenho, decorar e explicar o que entendi da lição. (Aluno I - grupo de discussão)

Bom, até aqui seria legal se a gente pudesse fazer um desenho na capa. Assim, a gente teria um tipo de caderno que quisesse. (Aluno 2 - grupo de discussão)

A capa do caderno foi relacionada à possibilidade de cada aluno ter seu material personalizado e à vontade de poder escolher seus materiais, no início do ano. Manifestaram, entusiasmados, experiências relativas a desejos e escolhas. Sobre o espaço, destacaram o quanto é complicado pensar na quantidade de linhas que são necessárias para responder a uma questão proposta e que, muitas vezes, o espaço que o professor indica não corresponde ao que eles consideram necessário para a resposta. A Aluna 4 assim se expressou: "A professora diz pra gente pular tantas linhas, mas eu sempre pulo mais, porque não vou deixar tudo amontoado", e foi acompanhada pela concordância dos demais.

Sobre a função do caderno, em meio às discussões, um aluno levantou-se, pediu a palavra e perguntou: "O que o caderno ensina pra vocês?" (Aluno I). De imediato, os demais sentiram-se desafiados a responder, falando, por exemplo, que "O caderno ensina tudo aquilo que você escreve nele, que ele ajuda a lembrar, para estudar e lembrar para a prova" (Aluno 4). Nesse ponto, o aluno questionador replica: "Decorar é uma coisa, aprender é outra! Minha pergunta ainda está de pé: o que o caderno ensina?" (Aluno I).

Esta questão pareceu incomodar a todos, a ponto de voltarem para a sala comentando-a. Relato posterior da professora da turma confirmou que eles continuaram a pensar e falar sobre 0 assunto, em sala. Sobre o aluno questionador, a professora contou que, em aula, ele já havia questionado a razão para copiar algumas coisas do quadro, da seguinte forma; "Professora, por que tem que copiar isso? Já 'tá' tudo aqui (apontando, com o indicador, para a cabeça)" (Aluno I).

O que os alunos pensam sobre a escola e seus processos de ensino revelam aspectos desconhecidos pelos professores e contribuem para superar práticas sedimentadas em concepções que devem ser superadas.

Olhar de professor, Ponta Grossa, v. 24, p. I-15, e-15398.004, 2021.

Disponível em <https://revistas2.uepg.br/index.php/olhardeprofessor> 
Relações entre professores, alunos e cadernos: sistematizações de uma pesquisa-intervenção

\section{A sistematização coletiva: sínteses provisórias}

a) As discussões durante a hora-atividade

O grupo de discussão com os professores da escola ocorreu durante a hora-atividade e durante uma reunião pedagógica. Considerando a realidade objetiva da organização da escola, nem sempre é possível reunir todos os profissionais ao mesmo tempo. Assim, foram feitos pequenos grupos para analisar as respostas obtidas nos questionários dos professores, pais e alunos. O objetivo foi provocar os professores a refletirem e abstraírem a essência das respostas coletadas.

Para mobilizar a discussão, foram lidas as respostas dos professores, dos estudantes e dos pais, bem como o conteúdo do grupo de discussão realizado com os alunos.

A análise da função e do uso do caderno suscitou, entre os professores, manifestações que trataram principalmente da organização desse artefato escolar. Para Lopes (2008, p. 190),

[...] o manejo dos cadernos escolares pressupõe algo mais do que apenas aprender a escrever. Requer, também, o aprendizado de uma organização gráfica. Como suporte de escrita, é um local onde se aprende uma estrutura de registro exclusiva da escola.

Os professores relataram o quanto os alunos perguntam aos professores sobre "Quantas linhas é para pular?", “É a lápis ou caneta?". Sobre isso, uma professora sintetiza: "É uma dependência, esse negócio de linha!"' (Professora 3).

A organização dos cadernos suscitou discussões a respeito do papel do professor na organização do caderno e das formas de organizações diferentes entre a educação infantil e o ensino fundamental. Para a Professora I, "quando você ensina, a organização é diferente de você deixar livre"; "primeiro, é preciso ter orientação para depois deixar a criança livre. Se a criança vem da educação infantil, a criança demora mais para se adaptar ao ensino fundamental".

Contrariando a posição da Professora I sobre primeiro orientar para depois deixar a criança livre, outras duas professoras pontuam: "Pois é, nós não damos autonomia" (Professora 3); “A criança vai se domesticar" (Professora 4).

Isto porque, na educação infantil, os instrumentos para registro e avaliação costumam ser diferentes daqueles utilizados no ensino fundamental. $\mathrm{Na}$ educação infantil são utilizados portfólios, onde são registrados os saberes e novos conhecimentos das crianças, através de desenhos, anotações, falas e fotos, por exemplo, que sejam significativos e tenham a identidade de cada um. Ao ingressar no ensino fundamental, ocorre uma ruptura, pois os cadernos, na maioria das vezes, são registros determinados e orientados pelo professor, estes, muitas vezes, não demonstram os saberes das crianças, mas sim os conteúdos trabalhados pelos professores. 
A partir da fala das professoras, é necessária uma reflexão sobre a autonomia e personificação dos cadernos. Se crianças com 3, 4 anos têm autonomia para organizar e fazer registros, ao seu modo, em seus cadernos, uma criança de 8, 9 anos não tem condições para fazer o mesmo? Será que os professores têm a necessidade de padronizar os cadernos para que se sintam mais organizados, para que tenham mais controle sobre seus estudantes?

Sobre o registro dos conteúdos no caderno, questionou-se o que os professores têm selecionado para a escrita dos alunos. Os professores destacaram que, no primeiro ano, o registro tem função diferente do realizado no quinto ano, por exemplo. Para a Professora 4, "o primeiro ano, é muito mais trabalho com organização de pequenas cópias". Para a Professora 8, "No caderno dos alunos são só registros de atividades", reforçando a ideia de que são privilegiadas muito mais as cópias do que formas diferenciadas de registros que indiquem trajetos pessoais dos estudantes.

Santos (2008) explica que o aluno é inserido na cultura escolar, ou seja, no conjunto de práticas e normas vigentes na instituição de ensino, exigindo saberes específicos para o uso do caderno. As exigências têm variações que dependem da metodologia utilizada, das condições concretas existentes, das organizações institucionais e das preferências dos professores.

Sobre a diferença do uso do caderno nos diferentes anos de escolarização, Santos (2008) explica que, por não ser algo natural, precisa ser ensinado. No entanto, o aprendizado gera, muitas vezes, sofrimento. As crianças têm muitas dúvidas a respeito das atividades de cópia do quadro, por exemplo, pois há ambiguidade e imprecisão em comandos como "façam como está no quadro", uma vez que os suportes são diferentes e as crianças não sabem em que momentos é possível fazer adaptações. Nos anos iniciais, o conteúdo dos cadernos é mais restrito a cópias e à resolução de exercícios com repostas simples. $O$ formato das atividades varia para as crianças maiores, pois os conteúdos dos cadernos tornam-se mais autorais.

b) As discussões durante a reunião pedagógica

Após as reflexões iniciais nos grupos de discussão com os professores, foi organizada uma reunião pedagógica que funcionou como o terceiro momento do grupo de discussão com a participação de todos os professores da escola.

Considerando a necessidade de discutir o protagonismo do aluno e a visão do caderno como ideia de processo de aprendizagem, a reunião começou com uma leitura provocativa "É tudo sorvete" (KRAMER, 2009), que expressa a ideia de uma criança que desenha livremente, desconsiderando o comando da professora. A escolha do texto foi intencional para provocar os professores a pensarem sobre a necessidade de livre expressão da criança. 
Relações entre professores, alunos e cadernos: sistematizações de uma pesquisa-intervenção

A provocação proposta pela leitura, seguida das sínteses dos questionários e grupos de discussão, levou a uma sistematização coletiva, marcada pelo envolvimento dos professores que desejavam manifestar sua opinião e relatar formas de trabalho desenvolvidas com os alunos que, muitas vezes, ficam invisíveis aos olhos de quem está de fora.

Motivada pelas discussões ocorridas nos pequenos grupos, uma professora compartilhou o livro Erro e Fracasso (AQUINO, 1997), comentando que, em casa, ficou pensando sobre as questões do questionário e da prática realizada na escola. Outras professoras falaram sobre intervenções que haviam realizado nos cadernos das crianças a partir das reflexões realizadas nos pequenos grupos durante a hora-atividade.

Os relatos que se sucederam levaram à sistematização de alguns pontos que evidenciam a reflexão sobre a prática e apontam para algumas possibilidades de reorganização da prática:

- Embora os professores tenham manifestado uma concepção de caderno como elemento para auxiliar o processo de aprendizagem, o mesmo não ocorreu no ponto de vista dos alunos. São enfatizados, pelos alunos, os conteúdos com fins de comprovação de aprendizagem e uma relação hierárquica entre professor e aluno, sendo o professor quem determina formas e registros. Essa relação precisa ser ressignificada.

- As discussões dos professores apontam para a necessidade de intervenções no caderno, não sendo ainda consenso que esse registro contribua para o processo de aprendizagem. A prática de "vistar" os cadernos ocorre em função de exigências externas e internas. É necessário ampliar as discussões a esse respeito para contribuir com o uso do caderno no processo de aprendizagem.

- As decisões sobre o conteúdo e as formas de registros desconsideram possibilidades diferenciadas, padronizando os cadernos e inviabilizando espaços de protagonismo do aluno. O portfólio é uma possibilidade para acompanhamento do processo de aprendizagem do aluno.

- Os questionamentos a respeito da organização do material escolar, como, por exemplo, a ideia do portfólio, estão intimamente relacionados ao protagonismo do aluno, sendo necessário repensar, para o próximo ano letivo, a lista de materiais a serem solicitados às famílias.

- As formas de organização dos materiais escolares na educação infantil são diferentes daquelas do ensino fundamental, expressando uma ruptura na forma de conceber a apropriação dos espaços pela criança. É preciso priorizar o desenvolvimento da criança ao organizar a escola como um todo.

Olhar de professor, Ponta Grossa, v. 24, p. I-15, e-15398.004, 2021. 
- Se os familiares compreendem o uso do caderno descolado da função de acompanhamento do processo de aprendizagem do aluno, é necessário criar espaços para discutir e possibilitar a eles ressignificar o uso do caderno.

E foram esses pontos que, neste contexto, servem para pensar a prática pedagógica como dimensão da prática social voltada para os processos formativos dos professores.

Destaca-se, na discussão entre os professores mediada pelas coordenadoras, a elaboração do portfólio. Para Villas Boas (200I, p. 207), o portfólio apoia-se em princípios básicos: a construção pelo próprio aluno, possibilitando-lhe fazer escolhas e tomar decisões; a reflexão sobre as suas produções; a criatividade, porque $o$ aluno escolhe a maneira de organizá-lo e busca formas diferentes de aprender; a autoavaliação pelo aluno, porque ele está permanentemente avaliando o seu progresso; a parceria professor-aluno e entre alunos, eliminando-se ações e atitudes verticalizadas e centralizadoras; a autonomia do aluno perante o trabalho.

Ao colocar em pauta o portifólio como instrumento de avaliação com a função formativa centralizada no processo de acompanhamento da aprendizagem do estudante, o coletivo avança na proposta de transformar a prática a partir da análise dos problemas postos pela prática.

\section{Considerações finais}

A questão central proposta para discussão foi a relação professor, aluno e caderno, a partir do questionamento de familiares sobre a ausência de marcas, como correções, incentivos, pareceres escritos pelos professores, nos cadernos dos alunos.

A estratégia da pesquisa-intervenção foi escolhida, pois prioriza os sujeitos atuando no seu contexto, é direcionada pela ideia de processo de discussão coletiva e possibilita a intervenção na prática pedagógica como dimensão da prática social voltada para os processos formativos, pedagógicos, políticos e culturais.

Assim, ao serem gestadas práticas coletivas no interior da escola, a fim de buscar soluções para os problemas postos pela própria prática, elas se tornam autênticas e comprometidas com pequenas transformações necessárias.

Neste sentido é que a transformação da prática na escola sustenta-se em um processo metodológico que se fundamenta na proposta de sistematização coletiva do conhecimento (MARTINS, 1996).

Esta sistematização coletiva foi constituída por momentos, fundamentais e inter-relacionados, quais sejam: I) Caracterização e problematização da prática pedagógica dos professores de forma a captar como ela transcorre (a relação entre professor, aluno e caderno); 2) Explicação da prática 
Relações entre professores, alunos e cadernos: sistematizações de uma pesquisa-intervenção

mediatizada por um referencial teórico, entendendo que essa prática é uma síntese de múltiplas determinações (concepção de ensino, o uso do caderno, protagonismo infantil, função do portfólio); 3) Compreensão da prática no nível da totalidade, buscando as raízes mais profundas dos seus determinantes no nível da totalidade com discussões acerca dos determinantes históricos, sociais, políticos (este momento é contínuo e faz parte do processo formativo dos professores); 4) Elaboração de propostas para intervenção na prática (como realizar a intervenção no caderno do aluno e por quê).

Assim, ao retomar o objetivo de sistematizar descobertas e elaborações teóricometodológicas a partir de problemas da prática pedagógica, chegamos às sistematizações coletivas, que apontaram aspectos a serem observados na reformulação da prática de intervenção no caderno do aluno: repensar o protagonismo do aluno no uso dos cadernos; qualificar o caderno como instrumento de acompanhamento individual dos processos de aprendizagem; explicitar aos pais como ocorrem os processos de intervenção no caderno do aluno.

Concluindo, a pesquisa-intervenção assume um papel formativo com vistas à transformação da prática pedagógica. Para isso, é preciso compreendê-la em seus determinantes e elaborar propostas concretas de intervenção, seja para transformar a prática radicalmente, seja para dar mais consistência às iniciativas já tomadas pelo professor ao enfrentar as contradições inerentes ao cotidiano pedagógico.

\section{Referências}

AQUINO, J. G. Erro e Fracasso na Escola: alternativas teóricas e práticas. São Paulo: Summus, 1997.

BERNARDO, J. Economia dos Conflitos Sociais. 2. ed. São Paulo: Expressão Popular, 2009.

CHARTIER, A. Os cadernos escolares: organizar os saberes, escrevendo-os. Revista de Educação Pública, Cuiabá, v.16, n. 32, p. 13-33, 2007.

FLICK, U. Métodos de pesquisa: uma introdução à pesquisa qualitativa. Porto Alegre: Artmed, 2009.

GVIRTZ, S. EI Discurso Escolar a través de los Cuadernos de Clase. Argentina ( 1930 1970). Buenos Aires: Eudeba, 1999.

HÉBRARD, J. Por uma bibliografia material das escritas ordinárias: o espaço gráfico do caderno escolar (França - séculos XIX e XX). Trad. Laura Hansen. Revista Brasileira de História da Educação, Campinas, n.I, p.II5-4I, jan./jun. 200I.

HÉBRARD, J. Lo spazio grafico del quaderno scolastico in Francia tra Otto e Novecento. In: ANTONELLI, Quinto; BECCHI, Egle (ed.). Scritture Bambine: testi infantili tra passato e presente. Roma-Bari: Laterza, 1995. p. 145-175.

KRAMER, S. (org.). Retratos de um Desafio: crianças e adultos na educação infantil. Enunciados e expressões das crianças na creche. São Paulo: Ática, 2009.

Olhar de professor, Ponta Grossa, v. 24, p. I-15, e-15398.004, 2021.

Disponível em <https://revistas2.uepg.br/index.php/olhardeprofessor> 
LOPES, I. C. da R. Cadernos escolares: memória e discurso em marcas de correção. In: MIGNOT, Ana Chrystina Venâncio (org.). Cadernos a Vista: escola, memória e cultura escrita. Rio de Janeiro: EdUERJ, 2008. p. 187-204.

MARTINS, P. L. O. A relação conteúdo-forma: expressão das contradições da prática pedagógica na escola capitalista. In: VEIGA, I. P. A. (org.). Didática: o ensino e suas relações. Campinas: Papirus, 1996. p. 77-103.

MIGNOT, A. C. V. Um objeto quase invisível. In: MIGNOT, A. C. V. Cadernos a Vista: escola, memória e cultura escrita. Rio de Janeiro: EdUERJ, 2008. p. 7-I3.

MOREIRA, M. I. C. Pesquisa-intervenção: especificidades e aspectos da interação entre pesquisadores e sujeitos da pesquisa. In: CASTRO, L. R de; BESSET, V. L. (org.) Pesquisa-intervenção na Infância e Juventude. NAU: Rio de Janeiro, 2008. p. 409-432.

PERES, E.; PORTO, G. C. Concepções e práticas de alfabetização: $O$ que revelam cadernos escolares de crianças? GTI05894. Ufpel e UNIPAMPA, 2009. Disponível em: <http://www.anped.com.br>. Acesso em: I set. 2017.

SANTOS, A. A. C. Aprendendo a usar cadernos: um caminho necessário para a inserção na cultura escolar. In: MIGNOT, Ana Chrystina Venâncio (org.). Cadernos a Vista: escola, memória e cultura escrita. Rio de Janeiro: EdUERJ, 2008. p. I45-I59.

SANTOS, O. J. A questão da produção e da distribuição do conhecimento. Educação em Revista, Belo Horizonte, UFMG/FAE, p. 4-7, dez. 1984.

SOUZA, M. A. de. Sobre o conceito de prática pedagógica. In.: SILVA, M. C. B. da (org.). Práticas Pedagógicas e Elementos Articuladores. Curitiba: Universidade Tuiuti do Paraná, 20I6. Cap.2. p. $38-65$.

VILLAS BOAS, B. M. F. Avaliação formativa: em busca do desenvolvimento do aluno, do professor e da escola. In: VEIGA, I. P.A.; FONSECA, M. (org.). As Dimensões do Projeto Político-pedagógico: novos desafios para a escola. Campinas: Papirus, 200I. p. 175-2I2.

VIÑAO, A. Os cadernos escolares como fonte histórica: aspectos metodológicos e historiográficos. In: MIGNOT, A. C. V. (org.). Cadernos a Vista: escola, memória e cultura escrita. Rio de Janeiro: EdUERJ, 2008. p. I5-33.

Recebido em: 13 de maio de 2020.

Versão corrigida recebida em: I 3 de julho de 2020.

Aceito em: 23 de outubro de 2020.

Publicado online em: 05 de março de 202I.

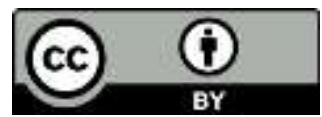

Olhar de professor, Ponta Grossa, v. 24, p. I-15, e-15398.004, 202 I.

Disponível em <https://revistas2.uepg.br/index.php/olhardeprofessor> 